\title{
Comparison of red blood profiles and oxygen transport capacity of elite and sub-elite wrestlers ${ }^{1}$
}

\author{
Mehmet Ozal ${ }^{2}$ \\ Asim Cengiz ${ }^{3}$ \\ Metin Yaman $^{4}$ \\ Mehmet Guclu ${ }^{5}$
}

\begin{abstract}
This study aimed to compare the red blood profiles' that are determinants of oxygen transports system, of elite wrestlers with sub-elite wrestlers. This study consists of a twenty-one elite wrestlers representing national team of Turkey who volunteered to participate in the study. Biochemical parameters were determined during transition period and the bloods were drawn in a resting state for each participant. A paired $\mathrm{T}$ tests was used to check the variations in hematological parameters. There are no significant differences between the groups except age. Elite wrestlers age was found to be significantly higher than sub elite wrestlers $(p=0.019<0.005)$. RBC, HGB, HCT, MCH, MCHC were within normal limits and also for athletes indicates a positive development and there were no significant differences between the groups. Training increases total hemoglobin mass by stimulating erythropoiesis, which increases the amount of $\mathrm{O} 2$ that can be carried by blood. regular screening of hematological variables is desirable as many athletes have values near or below the lower limit of the normal range.
\end{abstract}

Keywords: Red blood profiles; oxygen transport capacity; wrestlers.

\section{Introduction}

It was reported that the major tasks of red blood cells transmit the O2 (oxygen) from the lungs to the tissues and moving to the lungs expels the metabolically produced $\mathrm{CO} 2$. In the lung, inhaled oxygen (O2) diffuses from the alveolar membrane into blood, where the majority is added by hemoglobin (HGB) to form oxyhemoglobin process called oxygenation. HGB is contained in the red blood cells, being distributed by the cardiovascular system, transfers $\mathrm{O} 2$ to the periphery from its HGB bond (deoxygenation) and diffuses into the cells (Mairbäurl, 2013)

Hemoglobin and water are the major constituents of red blood cells (Gaeni, 2001). It was reported that hemoglobin contributes to the blood's buffering capacity, also ATP and nitric oxide secretion for the red blood cells that vasodilation and improved blood flow to working muscle (Mairbäurl, 2013). Red blood cells in circulation for these functions be present in sufficient quantities.

Oxygen carrying capacity of the blood is detrimental in performance of athletes. Thus, RBC

\footnotetext{
1 The summary of this study were presented as a poster at "The INWR annual scientific symposium at the world championships" in Las Vegas on 5th September 2015

2 Ph.D., Turkish General Directorate of Sports, Ankara, mehmetozal73@gmail.com

3 Asisst. Prof. Dr., Physical Education Department, Siirt University, awesome77@gmail.com

${ }^{4}$ Asisst. Prof. Dr., Physical Education Department, Gazi University, myaman@gazi.edu.tr

${ }^{5}$ Asisst. Prof. Dr., Physical Education Department, Gazi University, mguclu@gazi.edu.tr
} 

of elite and sub-elite yrestlers. Journal of Human Sciences, 13(2), 3614-3618. doi:10.14687/jhs.v13i2.3856

count, hemoglobin level and hematocrit level significantly control the capability of carrying oxygen to tissues and excretion of carbon dioxide [Gaeni, 2001]. The analysis of some of the parameters for evaluating the oxygen carrying capacity is required. These are mean hemoglobin concentration $(\mathrm{MCH})$, hematocrit (HCT), mean percent hemoglobin concentration (MCHC), and total red blood cell (RBC). It was confirmed that the biological vitality of $\mathrm{O} 2$ transfer by where declined $\mathrm{Hgb}-\mathrm{Hb}$ also reduces exercise performance in spite of a compensatory rise in cardiac output (Ledingham, 1977; Carroll, 2007), and by augmented aerobic performance upon increasing total Hgb.

Beydagi, et al, (1992) suggested that that the hematologic and biochemical parameters were altered depending on the type, intensity and duration of the exercises. Therefore, observing the trends of hematological variations consequential from conventional physical training in experienced wrestlers may grant a proper position for enhancement of the practical or destructive consequences of exercise programs. Therefore, considering the importance of concurrent wrestling programs prior to competition and the lack of adequate data on the impact of these programs on hematological parameters, in this study, we aimed to compare between the elite and sub-elite wrestlers of red blood cells which is determinant of the oxygen transport system.

\section{Methods}

Participants: In this study, the Turkish national team has been involved as a volunteer athlete from 21 elite wrestlers. Participant characteristics were presented in Table 1. Written and oral consent from each participant was obtained at the beginning of the study as they were informed of potential risks in the experiment. The participants were not informed of the outcomes until the study was concluded.

Procedures: Biochemical parameters were selected for the uptake of the rest of the season, and each participant's blood was taken in the resting state.

Blood Analysis: To evaluate the variations in hematological parameters following, $8 \mathrm{cc}$ venous blood samples from each participant in sitting position during transition session for each year from the competitions in resting state. Blood samples were directly referred to a legitimate clinical laboratory in test tubes containing anticoagulant, and the hematological parameters were determined using "Echo Biochemistry Analyzer".

Statistical Analysis: Kolmogorov- Smirnov test was used to determine data distribution. T-tests were used to check the variations in hematological parameters, with $\mathrm{p}$ values $<0.05$ considered significant. Data were analyzed on SPSS software version 16.

\section{Results}

There was no significant difference except for the age of the wrestlers in the findings. The age of elite wrestling was significantly higher than sub-elite wrestlers. $(p=0.019<0.005)$.

Table 1. Subject Characteristics

\begin{tabular}{lrrrrrr}
\hline & Group & $\mathrm{N}$ & Mean & $\mathrm{S}_{\mathrm{D}}$ & $\mathrm{T}$ & $\mathrm{P}$ \\
\hline \multirow{2}{*}{ Age } & $\mathrm{A}$ & 7 & 26.1429 & 2.60961 & 2.674 & $.019^{*}$ \\
\multirow{3}{*}{ Height } & $\mathrm{B}$ & 14 & 22.8571 & 2.74162 & & \\
\multirow{2}{*}{ Body Weight } & $\mathrm{A}$ & 7 & 174.7143 & 11.07120 & -.114 & .911 \\
& $\mathrm{~B}$ & 14 & 175.2857 & 10.43241 & & \\
& $\mathrm{~A}$ & 7 & 81.5714 & 21.97618 & -.151 & .883 \\
\hline
\end{tabular}

$*(p=0.000<0.005)$. 
Ozal, M., Cengiz, A., Yaman, M., \& Guclu, M. (2016). Comparasion of red blood profiles and oxygen transport capacity of elite and sub-elite yrestlers. Journal of Human Sciences, 13(2), 3614-3618. doi:10.14687/jhs.v13i2.3856

According to Table 2: RBC, HGB, HCT, MCH, MCHC values were within normal limits. There was no significant difference between the results was a positive indicator of the status and values.

Table 2 Erythrocyte Parameters $(\mathrm{n}=21)$

\begin{tabular}{|c|c|c|c|c|c|c|}
\hline & Group & $\mathrm{N}$ & Mean & $\mathrm{S}_{\mathrm{D}}$ & $\mathrm{t}$ & $\mathrm{P}$ \\
\hline \multirow{2}{*}{$\mathrm{RBC}$} & $\mathrm{A}$ & 7 & 5.1271 & .27615 & \multirow{2}{*}{-1.096} & \multirow{2}{*}{.292} \\
\hline & B & 14 & 5.2721 & .30395 & & \\
\hline \multirow{2}{*}{$\mathrm{HGB}(\mathrm{g} / \mathrm{dL})$} & A & 7 & 14.9286 & .87695 & \multirow{2}{*}{-.285} & \multirow{2}{*}{.780} \\
\hline & B & 14 & 15.0500 & 99981 & & \\
\hline \multirow{2}{*}{ HCT $(\%)$} & A & 7 & 45.7143 & 3.39481 & \multirow{2}{*}{-.172} & \multirow{2}{*}{.867} \\
\hline & B & 14 & 45.9714 & 2.86099 & & \\
\hline \multirow{2}{*}{$\mathrm{MCV}$} & A & 7 & 89.0857 & 4.21562 & \multirow{2}{*}{.910} & \multirow{2}{*}{.380} \\
\hline & B & 14 & 87.3000 & 4.28091 & & \\
\hline \multirow{2}{*}{$\mathrm{MCH}(\mathrm{pg})$} & A & 7 & 29.0857 & .59841 & \multirow{2}{*}{1.287} & \multirow{2}{*}{.216} \\
\hline & B & 14 & 28.2929 & 2.14349 & & \\
\hline \multirow{2}{*}{$\mathrm{MCHC}(\mathrm{g} / \mathrm{dL})$} & A & 7 & 32.6714 & 1.06413 & \multirow{2}{*}{-.096} & \multirow{2}{*}{.925} \\
\hline & B & 14 & 32.7214 & 1.24849 & & \\
\hline \multirow{2}{*}{ RDW (\%) } & A & 7 & 13.3286 & .63170 & \multirow{2}{*}{2.194} & \multirow{2}{*}{.063} \\
\hline & B & 14 & 12.7786 & .28603 & & \\
\hline
\end{tabular}

$*(\mathrm{p}=0.000<0.005)$. RBC (Red Blood Cell), HGB (Hemoglobin), HCT (Hematocrit), MCV (Mean Corpuscular Volume), MCH (Mean Corpuscular Hemoglobin), MCHC (Mean Corpuscular Hemoglobin Concentration), RDW (Red Cell Distribution Width)

\section{Discussion}

The long-term exercises can cause hematologic changes (Meyer and Meister, 2011). In this study, we aimed to compare between the elite and sub-elite wrestlers of red blood cells, which is determinant of the oxygen transport system.

It was reported that a high level of Hct increases blood viscosity and increases the work load of the heart (El-Sayedetal., 2005; Böning et al., 2011). Thus, this increase may cause the risk of cardiac overload. In the present study, it was found that elite wrestlers and sub-elite wrestlers had similar Hct values. Previous studies indicated conflicting results about Hct values of elite athletes. Several studies showed lower Hct in athletes than in sedentary subjects (Davies and Brewer, 1935; Ernst, 1987; Sawka et al., 2000). Sharpe et al. (2002) and Heinicke, et al, (2001) found that there were an inverse association between Hct with VO2, max except a small percentage of population in some studies. According to Cinar et al. (2013) study on footballers, even program of 10 days has caused noteworthy changes in complete blood values of RBC, PLT and HGB values. In the present study, similar red blood volume, $\mathrm{Hb}$ and total hemoglobin values were determined between two groups. It was stated that exercise increases total hemoglobin mass by stimulating erythropoiesis, which augments the amount of $\mathrm{O} 2$ that can be carried by blood. It was reported that an increase in

tHb by $1 \mathrm{~g}$ achieved e.g., by administration of erythropoietin, increased VO2, max by $\sim 3 \mathrm{ml} / \mathrm{min}$ (Schmidt and Prommer, 2010). Thus, augmented tHb and tEV in trained athletes proves that exercise stimulates erythropoiesis. Previously Ozal (2015) stated that the increase in red blood cells, and decrease cholesterol and urea values of the wrestlers after wrestling season are positive signs of improvements in hematological parameters of the wrestlers. 

of elite and sub-elite yrestlers. Journal of Human Sciences, 13(2), 3614-3618. doi:10.14687/jhs.v13i2.3856

\section{Conclusion}

The present study indicated that elite wrestlers had normal range of red blood profiles. This implies that training status of them had a positive effect on their regular red blood profiles. It was confirmed that during exercise the increased O2 demand of skeletal muscle is mainly matched by augmented muscle blood flow by increasing cardiac output, by modulating blood flow distribution among active and inactive organs, and by optimizing microcirculation (Laughlinetal, 2012).

\section{Acknowledgement}

I would like to thank SESAM (Athletes Training and Research Centre) health care professionals who worked with, especially for blood sampling and laboratory analysis.

\section{References:}

Banfi, G., Lundby, C., Robach, P., and Lippi, G. (2011). Seasonal variations of hematological parameters in athletes. Eur.J.Appl.Physiol. 111, 9-16. doi: 10. 1007/s00421-010-1641-1

Beydag1, H., B. Çoksevim, S. Temoçin, S. Akar, et al., (1992). Effect of acute submaximal exercise on the coagulation of persons doing and not doing sports. Sports Medicine Maga., 27:113-119

Böning, D., Maassen, N., and Pries, A. (2011). The hematocrit paradox-how does blood doping really work. Int.J.SportsMed. 32,242-246. doi:10.1055/s-0030-1255063

Carroll, S.B.(2007). The MakingoftheFittest. New York, NY: Norton.

Cinar V, Cengiz S, Pala R, Dündar A (2013). Effect of football practices on certain blood values of athletes. Advances in Environmental Biology, 7(5): 924-927.

Davies, J.E., and Brewer, N. (1935). Effect of physical training on blood volume, hemoglobin, alkali reserve and osmotic resistance of erythrocytes. Am.J.Physiol. 113, 586-591. doi: 10.3181/00379727-32-8059P

Diaz, V., Lombardi, G., Ricci, C., Jacobs, R.A., Montalyo, Z., Lundby, C., et al. (2011). Reticulocyte and hemoglobin profiles in elite triathletes over four consecutive seasons. Int.J.Lab.Hematol. 33, 638-644. doi:10.1111/j.1751- 553X. 2011.01348. X

El-Sayed, M.S., Ali,N., and El-Sayed, A.Z. (2005). Haemorheology in exercise and training. SportsMed. 35, 649-70. doi: 10. 2165/00007256-200535080-00001

Ernst, E. (1987). Influence of regular physical activity on blood rheology. Eur.Heart J. 8(Suppl.G),59-62. doi: 10. 1093/eurheartj/8. Suppl G.59

Gaeini AA. (2001). Comparing the effect of a maximal exercise and exercise under maximal on the response hematological factors of adolescent athletes and non-athletes, J Mov 10: 125-135. (Persian)

Ledingham, I.M. (1977). Factors influencing oxygen availability. J.Clin.Pathol. Suppl (R.Coll.Pathol.) 11,1-6. doi: 10.1136/jcp. s3-11.1.1

Magnusson, B., Hallberg, L., Rossander, L., and Swolin, B. (1984). Iron metabolism and "sports anemia". II. A hematological comparison of elite runners and control subjects. ActaMed.Scand. 216, 157-164. doi:10.1111/j. 0954- 6820. 1984. tb 03787.x

Mairbäurl H. Red blood cells in sports: effects of exercise and training on oxygen supply by red blood cells. Front Physiol 2013; 4:332

Meyer T, Meister S 2011. Routine blood parameters in elite soccer players. Int J Sports Med, 32(11): 
$875-881$

Ozal, M. (2014). Effects of a yearlong wrestling training season on biochemical blood parameters of elite wrestlers. Anthropologist, 18(3): 691-696 (2014)

Remes, K. (1979). Effect of long-term physical training on total red cell volume. Scand. J.Clin.Lab.Invest. 39, 311-19. doi:10.3109/00365517909106114

Sawka, M. N., Convertino, V. A., Eichner, E. R., Schnieder, S. M., and Young, A. J. (2000). Blood volume: importance and adaptations to exercise training, environmental stresses, and trauma/sickness. Med.Sci.SportsExerc. 32, 332-348. doi:10.1097/00005768-200002000-00012

Schmidt, W., and Prommer, N. (2010). Impact of alterations in total hemoglobin mass on VO2, max. Exerc.SportSci.Rev. 38, 68- 75. doi: 10. 1097/JES. 0b013e3181d4957a

Selby, G.B., and Eichner, E.R. (1986). Endurances swimming, intravascular hemolysis, anemia, and iron depletion: new perspective on athlete's anemia. Am.J. Med. 81, 791-794. doi: 10.1016/0002-9343 (86) 90347-5

Sharpe, K., Hopkins, W., Emslie, K. R., Howe, C., Trout, G. J., Kazlauskas, R., et al. (2002). Development of reference ranges in elite athletes for markers of altered erythropoiesis. Haematologica 87, 1248-1257. 